\title{
A monitoring system for determination of real deck slab behaviour in prestressed box girder bridges
}

\author{
M.A. Treacy \& E. Brühwiler \\ Ecole Polytechnique Fédérale de Lausanne (EPFL), Switzerland
}

\begin{abstract}
Deck slabs of road bridges are particularly exposed to high numbers of fatigue inducing stresses. It can be difficult to accurately model their service behaviour as secondary elements such as parapets, kerbs and surfacing layers reduce the stress levels in the steel reinforcement bars. Changes in material properties over time and thermal variations further complicate the process. For these reasons a monitoring regime is favoured for the accurate determination of real 'action effects' within the bridge elements. This paper presents a 1960's prestressed concrete motorway bridge in Switzerland which is instrumented with a remotely accessible structural health monitoring (SHM) system. The key focus of the study is on the direct measurement of strains in reinforcement bars to provide a better understanding of the real structural behaviour of such bridges. The system is used to show the signature of an extreme vehicle crossing event as strain and vibrational response in the structural elements.
\end{abstract}

\section{INTRODUCTION}

\subsection{Overall Motivation}

The demand for more sustainable infrastructure requires road authorities to maximise the lifetimes of existing bridges whilst limiting resource usage during improvement interventions. This is complicated by substantial increases in the volume of heavy traffic in recent years. For example, estimates show that goods transport by road in tonne-kilometres has almost doubled in the period from 1985 to 2010 in the Western Europe EU-15 countries (Belluci et al. 2011) and this trend is also present in many other countries. While it is important to identify problematic bridges, it is also vital to avoid the condemnation of those performing adequately. This requires a better understanding of the loads acting on bridges and, in particular, the subsequent action effects within their elements.

Advanced technologies now exist for measuring a wide range of phenomena which must be exploited. With today's data storage and internet technologies, web based monitoring systems can now be developed at relatively low cost for the continuous monitoring of bridges. The next step is to efficiently process the monitored data and integrate the results within decision making strategies to allow adequate planning and resource allocation for interventions or replacements.

\subsection{Bridge action effects}

In many cases, bridges show significantly higher load carrying capacity than conventional calculation methods suggest. It is actually not obvious to simulate accurately the structural behaviour even with advanced numerical models as secondary elements such as parapets, kerbs and surfacing layers reduce the stress levels in the structure through structural behaviour or load distribution. Temperature and material property change over time can also have a large influence on the structural behaviour.

Burdet (1993) presented the results of over 200 load tests on Swiss bridges over a 20 year period showing significant structural contributions from the asphalt layer and parapets which would reduce deck stress levels, for example in steel reinforcement, and thereby prologue fatigue life. Castro (2003) showed that asphalt to deck slab bond stresses are largest in box girder bridges, which could suggest some structural function in certain cases. Penka (2005) examined the strong influences of the thermal loading in the longitudinal behaviour of prestressed box girders which can cause higher stress cycles than heavy traffic.

A number of recent studies have related crack widths in concrete to strains in reinforcement (Matsumoto \& Nazmul Islam 2005, Choi \& Oh 2009, Pircher et al. 2011) but there is still some uncer- 
tainty in the final answer due to the number of variables within the numerical models.

Bridge traffic loading can be improved by using local Weigh-in-Motion (WIM) data (Treacy \& Brühwiler, 2011) to develop more accurate load models but there is still much work to do in arriving at real action effects in the bridge elements. Moses (1979) and various subsequent researchers including Znidaric et al. (2008) have used the bridge structure as a weighing system by relating vehicle loads to strains in elements and this is known as Bridge Weigh-in-Motion (B-WIM).

\subsection{Relevance to prestressed box girder bridges}

Prestressed concrete box girders are a very common and efficient method of bridge construction. Perhaps $40 \%$ of highway bridges constructed in Switzerland since 1960 are of this form (Broquet, 1999).

With typical box girders the outer cantilever in particular is often subjected to greater fatigue cycles due to the heavy trucks in slow lane (where no emergency lane is present). No major fatigue failures of such elements have yet been reported but their widespread use only commenced in the mid 1960's therefore many are still less than 50 years old. Studies such as Schläfli and Brühwiler (1998) found that the reinforcement is the determinant fatigue element in the deck slabs of reinforced concrete bridges. Therefore certain details in such bridges require further examination to ensure their safety into the future.

\subsection{Approach}

For existing bridges it is possible to directly measure the bridge action effects therefore the traffic load is no longer of primary interest. This also removes the need for any dynamic or thermal considerations as they are directly included in the measurement results.

For structural safety verification, strain measurements are preferable over deflections as they correctly reflect the state of stress resulting from flexural moments (Ludescher and Brühwiler, 2009).

As it is impractical and uneconomical to instrument the whole structure the system based on the principle of one strategic location equipped with many different sensors was developed to provide a 'Smart Section' which allows measurement of multiple phenomena. The objective of this paper is to explain the methodology behind the monitoring system developed for a specific bridge with the goal of better understanding the true deck slab behaviour under long term traffic and environmental actions.

The aim in this case is not to study the problem of fatigue but to focus on accurate determination of the real strain behaviour in the deck slab reinforcement.

\section{BRIDGE MONITORING PROGRAMME}

\subsection{Overview}

Many Structural Health Monitoring (SHM) studies focus on either the monitoring of existing structures with problems or new, often complex structures with embedded sensors. However, this study focuses on determining action effects in a well performing bridge free from known defects or corrosion issues which would potentially affect the service behaviour. The results can then potentially be applied to more general cases on problematic bridges. A heavily trafficked bridge representative of the Swiss bridge stock was selected.

\subsection{Bridge site}

The monitored bridge was constructed around 1963 and is located on Swiss A1 motorway between Geneva and Lausanne. The structure (Fig. 1) consists of twin prestressed box girders of three spans with a total length of $110.5 \mathrm{~m}$. Average daily traffic volumes are in the region of 70,000 vehicles (FEDRO, 2011). The girders are prestressed longitudinally and also transversely in the upper flange.

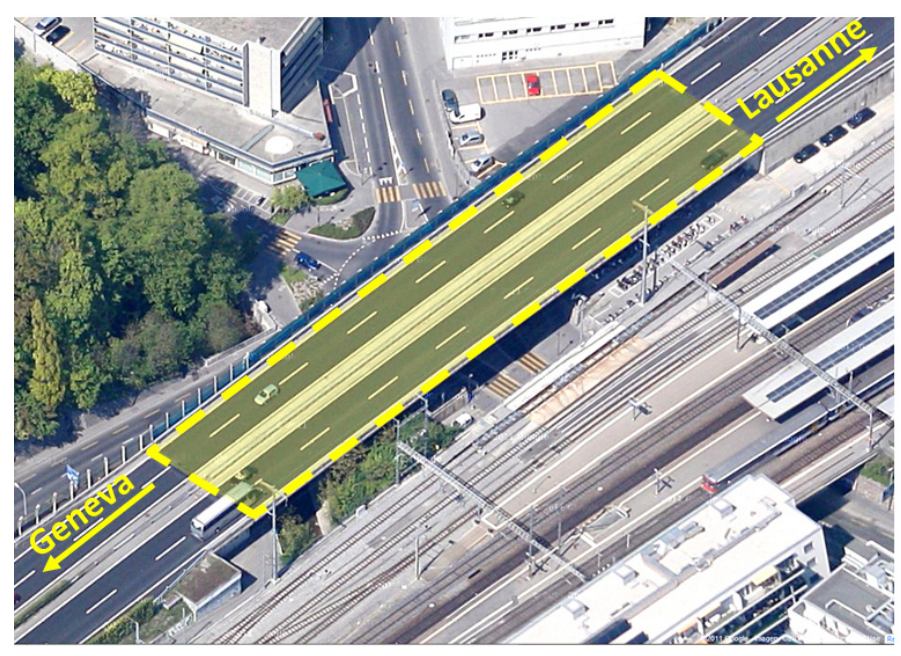

Figure 1. Aerial view of bridge (www.googlemaps.com).

\subsection{Monitoring system overview}

The centre of the inner span was selected for the Smart Section (Fig. 2) as it provides good information on both the lateral and transverse behaviour. As the 2 girders in each direction are completely identical but separated structures only 1 girder was instrumented for this study.

In more complex structures or where specific issues are to be examined, for example, fatigue of coupling joints, the position must be adjusted and more than one section may be required. 

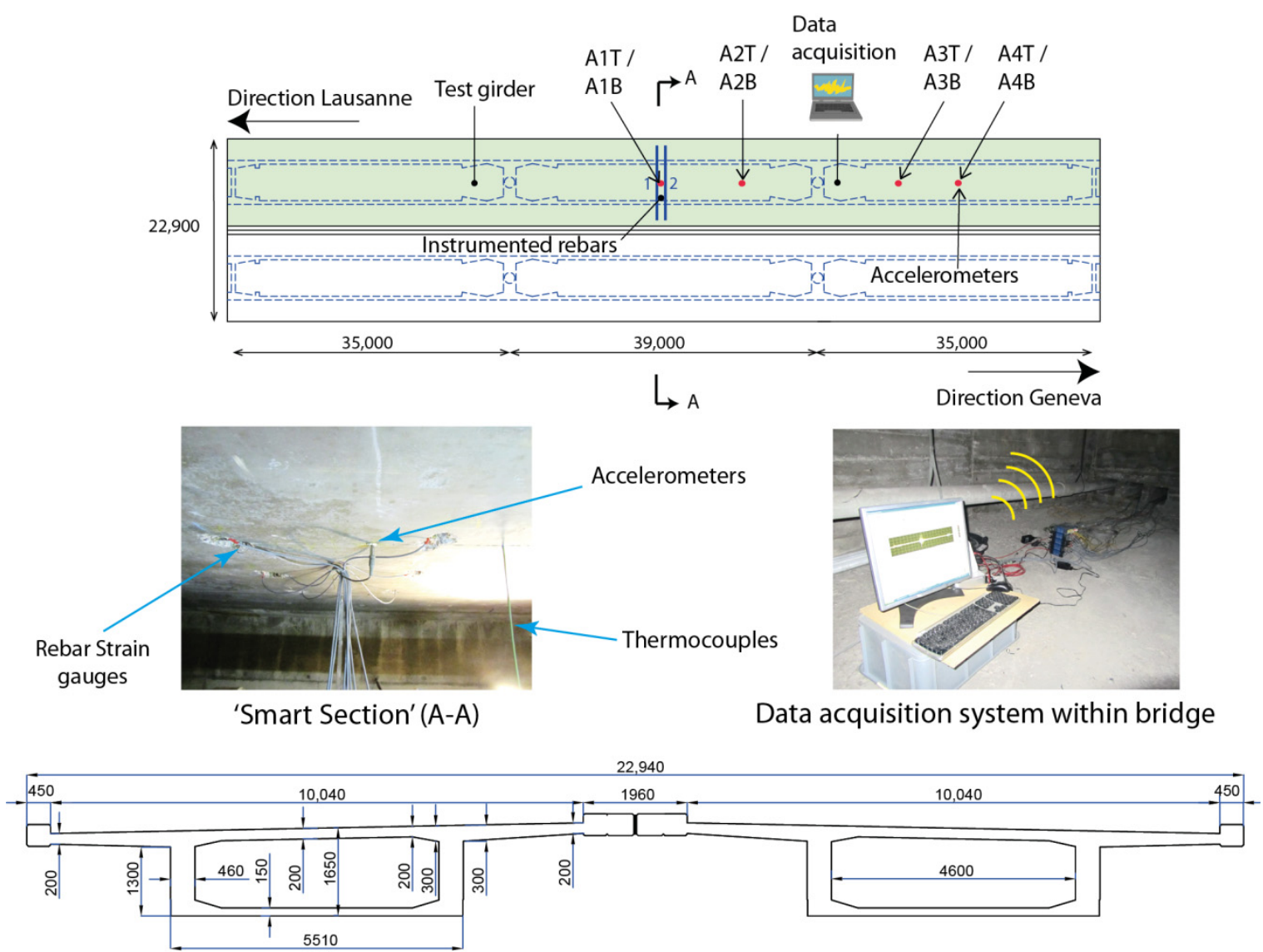

Bridge Cross Section

Figure 2. Schematic of monitoring system.

The system is fully accessible remotely via a wireless internet connection within the bridge allowing constant access for data transfer and modification of the measurement programme. Accelerometers are used for the characterization and monitoring of the bridge's global dynamic behaviour and to assist decision making on sampling rates for strain gauge monitoring. During this part of the study eight accelerometers were placed on the bridge at four longitudinal locations (Fig 2). At these positions one accelerometer was fixed to the top of the lower flange and one to the underside of the upper flange.

The system features strain gauges on the uncracked concrete surface and steel reinforcement bars, thermocouples and accelerometers as illustrated in Figures 2 and 3. Two transverse reinforcement bars were each instrumented with electrical resistance strain gauges as shown in Figures 3 and 4. In addition two neighbouring bars in the longitudinal direction were instrumented. The gauges on the concrete surface $\mathrm{C} 1-\mathrm{C} 5$ are oriented in the transverse direction and $\mathrm{C6}-\mathrm{C} 8$ are oriented in the longitudinal direction.

In order to limit damage to the concrete structure to an absolute minimum, GPR (ground-penetrating radar) techniques as described in Hugenschmidt and Kalogeropoulos (2009) were used to locate the reinforcement bars to be instrumented.

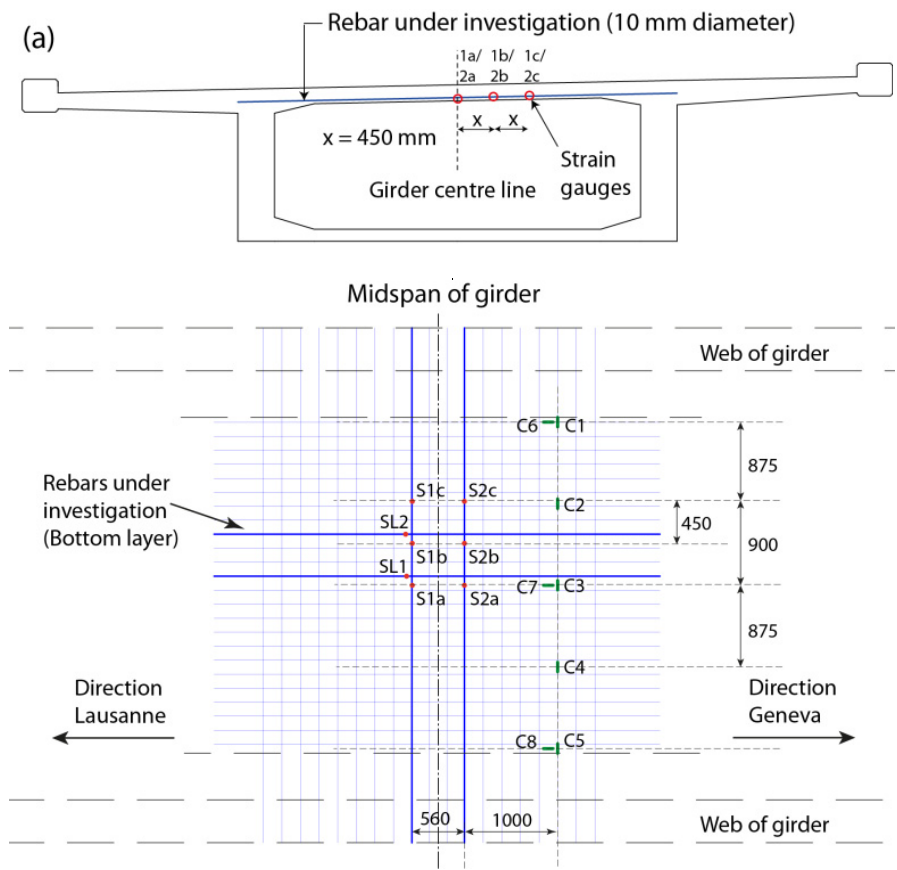

Figure 3. (a) Section showing strain gauges on transverse reinforcement bars and; (b) Plan of strain gauges on underside of deck slab at 'Smart Section'.

The strain gauges on the reinforcement bars are arranged in half bridge configurations incorporating compensation strain gauges on steel plates to avoid 
problems with temperature drift (Fig. 4). The strain changes in the non-structural steel plate are removed from the strains in the bar to provide a resultant strain in the bar free of local thermal expansion effects. Global temperature effect is dealt with later in the paper.

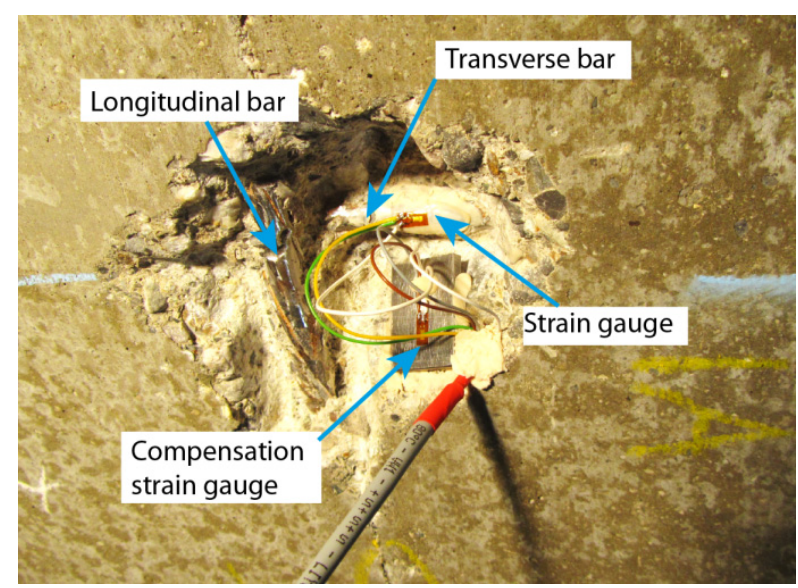

Figure 4. Strain gauges on transverse bars with local temperature compensation.

The positions of the accelerometers and concrete strain gauges on the Smart Section are shown in Figure 5a (on plan in Fig. 3b). In order to examine the thermal effects on the measured strains a series of thermocouples were provided. They were drilled $30 \mathrm{~mm}$ into the concrete. Air temperature and relative humidity were also recorded inside the girder with a separate system. The two-dimensional stress state in the slab can be examined by providing pairs of strain gauges $10 \mathrm{~cm}$ long on the concrete structure in two orthogonal directions as shown in Figure $5 \mathrm{~b}$.
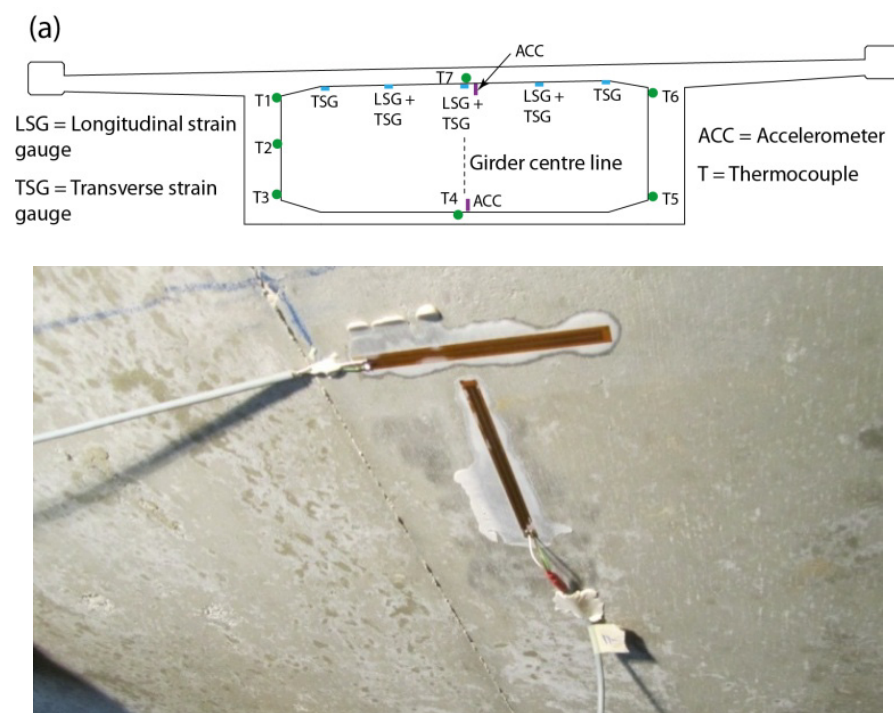

Figure 5. (a) Locations of sensors on Smart Section and; (b) $10 \mathrm{~cm}$ strain gauges glued directly to the uncracked concrete.
As the study is concerned with service stress cycles the gauges can be zeroed each morning so long term drift is not a problem. This means the results are reference free but the inherent self-weight stresses in the elements are not of interest.

Once operational, all of the measurable parameters can be viewed on the control panel display of the monitoring software as demonstrated in Figure 6. An interface for the monitoring system was written in the Lab View software allowing alteration to monitoring regimes and providing 'on line' visualisation of data being recorded.

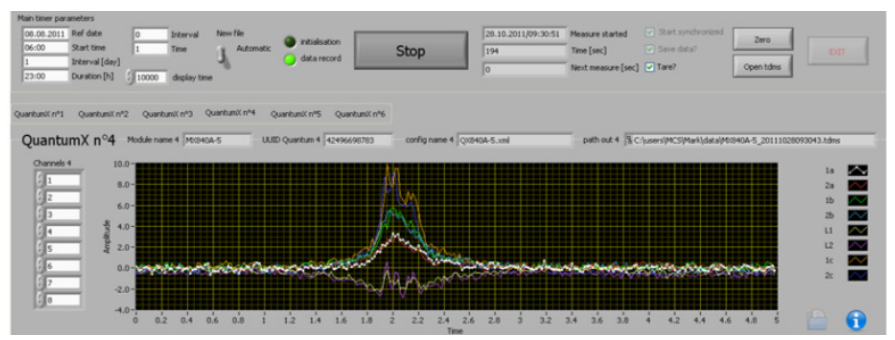

Figure 6. Screenshot of monitoring interface showing the live response due to a truck as transverse strain in reinforcement bars (Top).

\subsection{Calibration}

The monitoring system was calibrated using a 'soft loading' technique with a five axle mobile crane of 58.8 tonnes. The truck was driven over the bridge (with limited normal traffic) at various speeds and lateral positions to assess dynamic amplification and load distribution behaviour (Fig. 7).

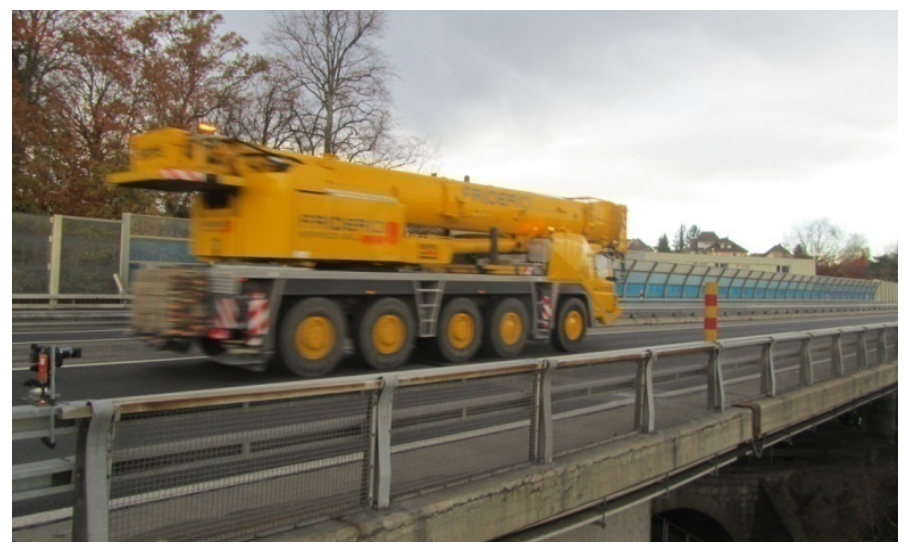

Figure 7. Test vehicle crossing bridge during monitoring system calibration. 


\section{MEASURED BRIDGE BEHAVIOUR}

\subsection{Dynamic behaviour}

The bridge dynamic behaviour was assessed by ambient vibration testing, using the traffic as the excitation mechanism. A sensitivity study was performed on the accelerometer data using sampling rates of $50,100,150$ and $200 \mathrm{~Hz}$. The measured dynamic responses were used to estimate the natural frequencies of the structure which was required for determination of sampling rates for other sensors as well as validation of separate finite element studies.

The recorded accelerations were transferred to the frequency domain using a fast Fourier transform given by equation 1 below (Bringham and Morrow, 1967):

$\mathrm{X}_{\mathrm{k}}=\sum_{\mathrm{n}=0}^{\mathrm{N}-1} \mathrm{x}_{\mathrm{n}} e^{-i 2 \pi k \frac{n}{N}} \quad$ For $\mathrm{k}=0, ., \mathrm{N}-1$

The acceleration results in Figure 8 show a maximum peak in the frequency spectrums around $2.7 \mathrm{~Hz}$ indicating the first natural frequency of the structure with an air temperature of $12{ }^{\circ} \mathrm{C}$ inside the box girder. This has been found to rise as high as $3.1 \mathrm{~Hz}$ in freezing temperatures. The $2^{\text {nd }}$ and subsequent modes can be observed as a series of lower amplitude peaks.

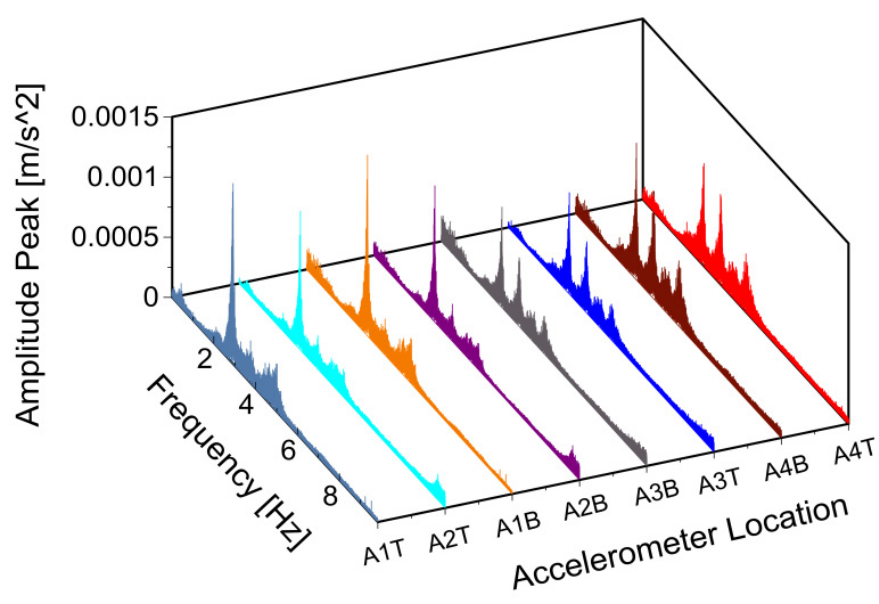

Figure 8. Frequency spectrums of accelerometers for 1 hour measuring period at $100 \mathrm{~Hz}$ sampling rate.

\subsection{Strain in reinforcement}

The key focus of this work was to accurately determine the stresses in the steel reinforcement. The three gauge arrangement shown in Figure 3a allows the capture of the movement in the positive trans- verse bending moment of the deck slab which is dependent on the vehicle axle positions. Figure 9 presents the results of three strain gauges installed on one of the two instrumented transverse reinforcement bars.

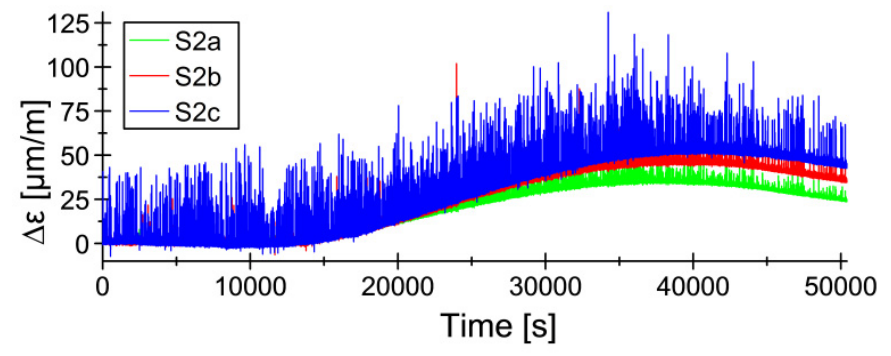

Figure 9. Tensile strain changes at 3 locations on selected reinforcement bar over 14 hour period in October 2011.

These strains are converted to stresses using Hooke's law if required but the low strain levels of maximum $50 \mu \varepsilon$ (corresponding to a stress range of approximately $10 \mathrm{MPa}$ ) during this short time period mean that fatigue safety is not an issue in this particular bar. This is further helped by the fact that the bars are generally in compression due to the transverse prestressing in the deck slab. The effect of temperature is evident in figure 9 and is discussed further in section 3.5.

\subsection{Strain in concrete}

As there were questions relating to the effect the local removal of concrete would have on the steel bar behaviour; strain gauges were placed close by on the concrete surface to ensure the behaviour is similar. As these gauges are further away from the neutral axis than those on the steel bars the measured strain amplitudes will be slightly higher but the behaviour should be very similar. Results of the measured strains on the uncracked concrete surface are shown in Figure 10 below (See Figs. 3/5 for locations). These signals are observed to be 'noisier' than the steel gauges at lower relative strain levels which may be due to the damping out of slab vibration. The effect of temperature is evident in figure 10 and is discussed further in section 3.5. 


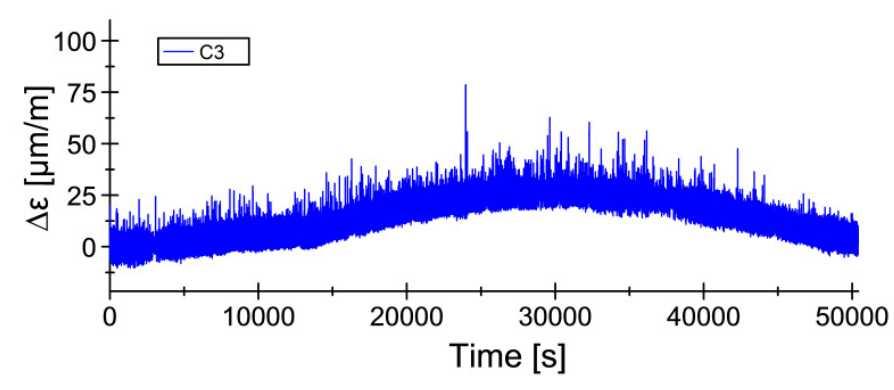

Figure 10. Transverse slab strain changes on underside of concrete deck slab over 14 hour period in October 2011.

\subsection{Observation of extreme events}

Although the measured strains are small the system can be used to observe extreme events which may cause damage elsewhere in the structure or on neighbouring bridges. This is demonstrated with the test vehicle shown previously in Figure 7. The individual test run to be presented was carried out with the vehicle in the slow lane of the (2 lane) bridge with a constant velocity of $45 \mathrm{~km} / \mathrm{hr}$. In Figure 11 the five peaks associated with the five vehicle axles are clearly visible in the strain diagram in both the transverse and longitudinal steel bars. The lower curve for the longitudinal bars traces the vehicles arrival on the bridge at approximately 703.5 seconds and departure at approximately 711 seconds.
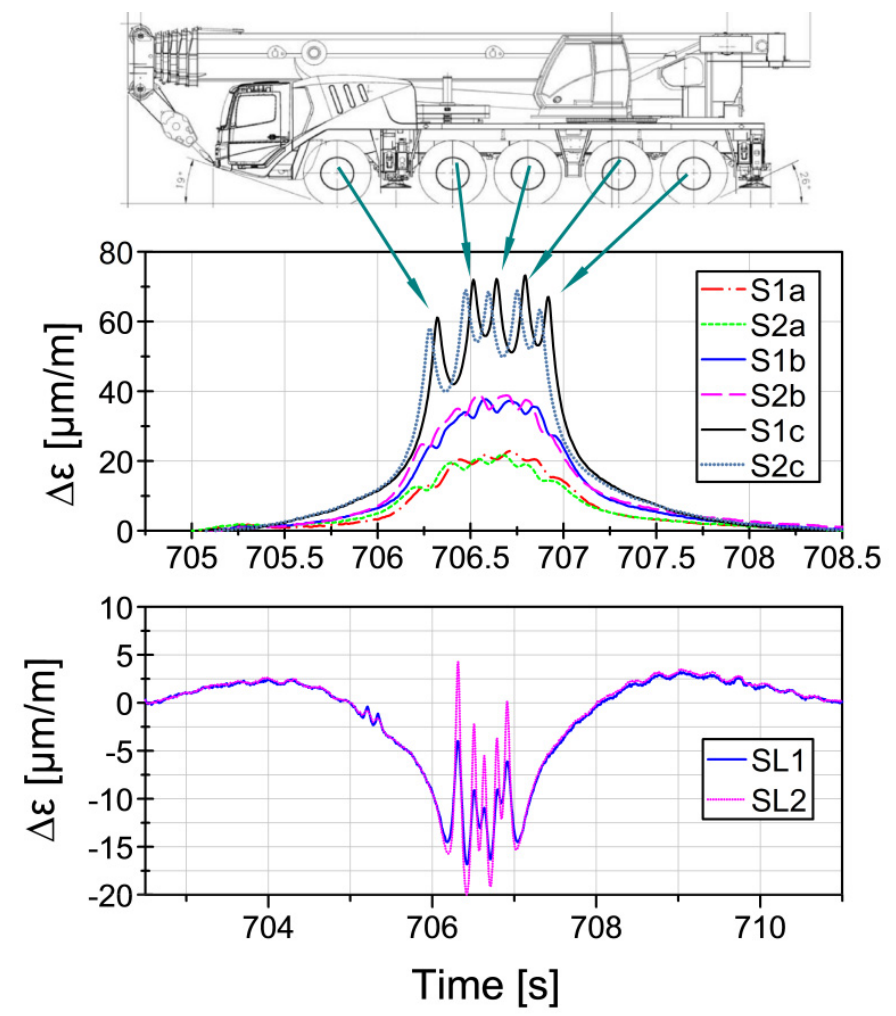

Figure 11. Signature of extreme vehicle seen as: (a) Influence on transverse reinforcing bar tensile strains and; (b) Influence on longitudinal bar strains from start of bridge to end.
Confidence in the system was assured by observing the behaviour of sensors at the same lateral position on different bars. i.e. S1a/S2a, S1b/S2b, $\mathrm{S} 1 \mathrm{c} / \mathrm{S} 2 \mathrm{c}$ and SL1/SL2 which show an excellent correlation.

In this particular case this extreme vehicle has no fatigue damaging effect on the reinforcement based on current theories of a constant steel fatigue limit but it validates the hypothesis that an individual bar element in the structure can be used to capture the passing of such vehicles. The measured information can also be used in further studies to assess the dynamic amplification of static load considering various different vehicle speeds.

\subsection{Thermal effects}

It is it evident that temperature change throughout the day has an obvious effect in both the steel reinforcement and the concrete deck slab which can be observed in the previous Figures 9 and 10, respectively. In both cases the traffic induced strains are observed almost as 'noise' on an overall temperature affect curve throughout the day. The overall thermal strain is seen to rise from the starting time of 6am through the middle of the day and fall again at night (end of monitoring 8pm).

If examinations of traffic-only action effects are required then a data treatment process can remove this temperature wave as demonstrated in Figure 12 for a transverse deck slab reinforcement bar. The lower curve shows only the traffic cycles allowing easier identification of extreme heavy vehicle events. It is not yet known if a heavy vehicle event has the same action effect in a bar if there is a significant difference in temperature from the case analysed.

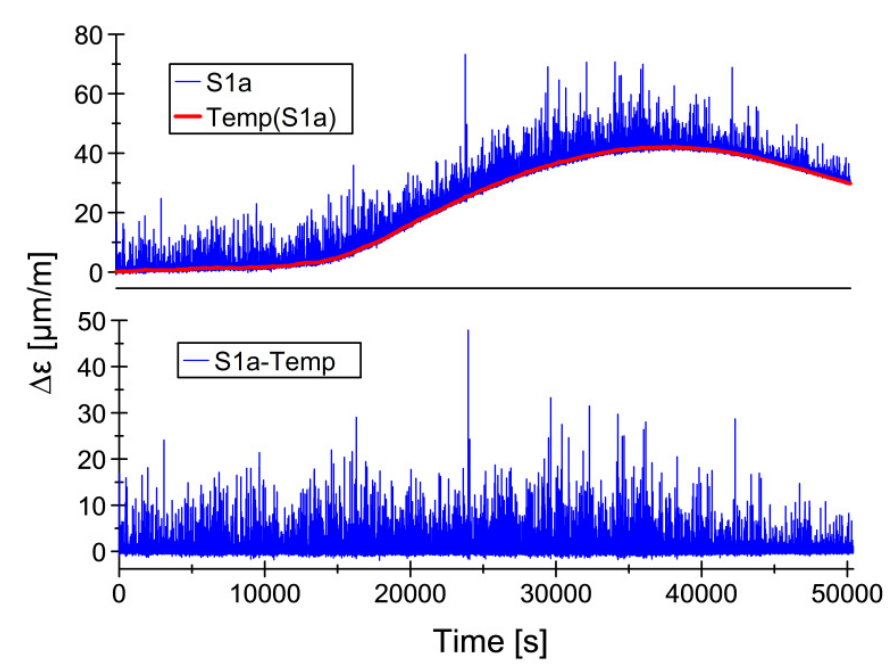

Figure 12. (a) Reinforcing bar strain profile affected by thermal gradient (in red) and; (b) Strain after removal of thermal effect. 


\subsection{Cross comparison of results}

The main aim of the strain gauges on the concrete structure was to validate those on the steel reinforcement bars and offer a point of cross reference. Figure 13 below illustrates the crossing of a heavy vehicle as seen within the strain profile of a reinforcement bar and adjacent on the concrete slab. Both sensors are located in the same transverse position (the centre of the section) in order to compare transverse bending induced strain between the two. A slightly smaller overall amplitude is seen in the rebar for the reasons discussed in section 3.3 but the strain profile shape is almost identical. Note that the overall thermal wave varies for the two different sensors with divergence evident.

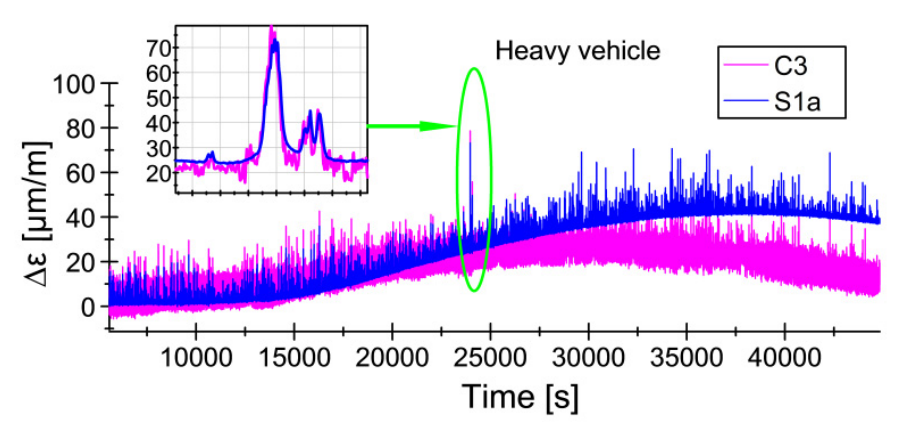

Figure 13. Comparison of strain in reinforcement bar (S1a) and adjacent concrete (C3) during 14 hour period in October 2011.

\section{CONCLUSIONS}

Latest sensing and data retrieval technologies have been implemented to demonstrate the monitoring of a Smart Section as a suitable approach to determine the real behaviour in deck slabs of prestressed boxgirder bridges.

The installed instrumentation allows accurate and reliable readings of relevant bridge deck data, in particular the capture of very small strain values. This direct measurement approach can overcome many of the uncertainties associated with modelling of surfacing and secondary elements as well as thermal and dynamic effects.

This recorded data allow for a first evaluation of the fatigue and structural safety of a given element and is a direct approach to answering the question: "is there enough safety?"

\section{FUTURE WORK}

A crucial issue as regards data interpretation is the comparison of measured and calculated data in order to verify the effectiveness and efficiency of the monitoring system (fib, 2003). A separate analytical study of the same bridge with current traffic load information has found significantly higher strains in the elements and further work is required to explain this. The aforementioned effects of parapets, kerbs and surfacing layers will have some beneficial effect. Detailed computer modelling with 3D solid elements will be carried out to examine this further.

\section{ACKNOWLEDGMENTS}

The authors are grateful for the funding provided under the TEAM project, a Marie Curie Initial Training Network funded by the European Commission 7th Framework Programme (PITN-GA-2009238648).

They would like to thank the Swiss Federal Roads Authority (FEDRO) for providing permission and access to the bridge used in this study.

Gratitude is also expressed to Gilles Guignet and Gerald Rouge of the EPFL structures lab for assistance in developing the monitoring software and installation of the sensors respectively. 


\section{REFERENCES}

Bellucci, P., di Roma, C., Fusco, G. \& La Monica, S. 2010. FEHRL Vision 2025 for Road Transport in Europe. Available at:

www.fehrl.org/?m=32\&mode $=$ download\&id file $=184$

Bringham, E.O. \& Morrow, R.E. 1967. The fast Fourier transform. IEEE Spectrum 4: 63-70.

Broquet, C. 1999. Comportement dynamique des dalles de roulement des ponts en béton sollicités par le trafic routier. PhD Thesis, Ecole Polytechnique Fédérale de Lausanne (EPFL), Lausanne.

Burdet, O. 1993. Load testing and monitoring of Swiss bridges. CEB Bulletin d'Information, Safety and Performance Concepts 219. Lausanne.

Castro, M. 2004. Structural design of asphalt pavement on concrete bridges. Canadian Journal of Civil Engineering 31: 695-702.

Choi, Y.C. \& Oh, B.H. 2009. Crack Width Formula for Transversely Post-Tensioned Concrete Deck Slabs in Box Girder Bridges. ACI Structural Journal 106 : $753: 761$.

FEDRO. 2011 Route et traffic, Chiffres et faits. Swiss Federal roads Authority, Bern. Available at:

http://www.astra.admin.ch/dokumentation/00119/04504/ind ex.html?lang $=\mathrm{fr}$

fib Bulletin 22. 2003. Monitoring and safety evaluation of existing concrete structures. International Federation for Structural Concrete, Lausanne.

Hugenschmidt, J. \& Kalogeropoulos, A. 2009. The inspection of retaining walls using GPR. Journal of Applied Geophysics 67: 335-344.

Ludescher, H. \& Bruhwiler, E. 2009. Dynamic amplification of traffic loads on road bridges. Structural Engineering International 19(2): 190-197.

Matsumoto, T. \& Nazmul Islam, M. 2005. Determination of rebar forces based on the exterior crack opening displacement measurement of reinforced concrete. In Farhad Ansari (ed.), Sensing Issues in Civil Structural Health Monitoring, 175-183. The Netherlands: Springer.

Moses, F. 1979. Weigh-In-Motion System using instrumented Bridges, ASCE Transportation Engineering Journal 105 233-249.

Penka, E. 2005. Beurteilung der Ermüdungssicherheit von Koppelfugenquerschnitten bestehender Spannbetonbrücken durch Langzeitmessungen. PhD Thesis. Technical University of Munich.

Pircher, M., Lechner B., Mariani, O. \& Kammersberger, A. 2011. Damage due to heavy traffic on three RC road bridges. Engineering structures (Article in Press).

Schläfli, M. \& Brühwiler, E. 1998. Fatigue of existing reinforced concrete bridge deck slabs. Engineering structures 20: 991-998.

Treacy, M. \& Brühwiler, E. 2011. Fatigue load estimation for road bridges using long term WIM monitoring. In Christophe Berenguer, Antoine Grall, Carlos Guedes Soares (eds), Advances in Safety, Reliability and Risk Management: ESREL Conference 2011. London: CRC Press.

Znidaric, A., Lavri, I. \& Kalin, J. 2008. Measurements of bridge dynamics with a bridge weigh-in-motion system. International Conference on Heavy Vehicles, Paris. 